\title{
Past and future hydrological simulations of Chao Phraya river basin
}

\author{
Tetsuya Ogata ${ }^{1}$, Oliver C.SaavedraValeriano ${ }^{2}$, Chihiro Yoshimura ${ }^{3}$, \\ Winai Liengcharernsit ${ }^{4}$ and Yukiko Hirabayashi ${ }^{5}$
}

\footnotetext{
${ }^{1}$ Student Member of JSCE, Graduate student, Department of Civil Engineering, Tokyo Institute of Technology (2-12-1 Oookayama, Meguro-ku, Tokyo 152-0033, Japan)

${ }^{2}$ Member of JSCE, Dr. Eng., Associate Professor, Department of Civil Engineering, Tokyo Institute of Technology (2-12-1 Oookayama, Meguro-ku, Tokyo 152-0033, Japan)

${ }^{3}$ Member of JSCE, Dr. Eng., Associate Professor, Department of Civil Engineering, Tokyo Institute of Technology

(2-12-1 Oookayama, Meguro-ku, Tokyo 152-0033, Japan)

${ }^{4}$ Not Member of JSCE, Dr. of Eng, Associate Professor, Faculty of Engineering, Kassetsart University (50 Phaholyothin Road, Bangkok 10900, Thailand)

${ }^{5}$ Member of JSCE, Dr. Eng., Associate Professor, School of Engineering, The University of Tokyo (2-11-16, Yayoi, Bunkyo-ku, Tokyo 113-8656)
}

\begin{abstract}
Predictions of variations in global and regional hydrological cycles and their response to changes in climate and the environment are key problems for future human life. Therefore, basin-scale hydrological forecasts, along with predictions regarding future climate change, are needed in areas with high flood potential. This study forecasts hydrological process scenarios in the upper Chao Phraya River basin using a distributed hydrological model (DHM) and precipitation scenarios from three general circulation models modified by the $\mathrm{H} 08$ model. First, discharge was simulated by the DHM using the observed rainfall from 2007 to 2009 and then, future discharge scenarios from2010 to 2040 were forecast.
\end{abstract}

Key Words: Chao Phraya river, hydrological scenario, flood forecast, GCM

\section{INTRODUCTION}

Most of the heavy precipitation events in Southeast Asian countries occur during the monsoon season. This rainfall in these humid regions allows the production of many crops. In particular, Thailand is the world's biggest rice exporter, shipping about 10 million tons of milled rice annually, which accounts for about $34.4 \%$ of all exports worldwide. ${ }^{1)}$ However, seasonal differences in precipitation and over cropping may cause problems such as flooding, inundation, subsidence, sediment erosion, and deterioration of water quality.

Over the past 30 years, the number and impact of flood disasters across Asia have increased. ${ }^{3)}$ Moreover, the IPCC 4th Assessment Report states that the frequency of precipitation is likely to decrease, but rainfall intensity could increase. ${ }^{4)}$ These changes in precipitation patterns could cause seasonal changes in the problems mentioned above, especially flooding and sediment erosion. Therefore, river network discharge and sediment transportation predictions are necessary for watershed management.
Large unexpected floods occurred in 2010 and 2011. In the 2010 flood, 51 prefectures suffered flood damage and 260 people died. ${ }^{5)}$ In 2011, which was similar to 2010, continuous rainfall from May to October caused the worst flooding in Thailand's history; approximately 600 persons perished, and by early November, 58 provinces were affected.

These two floods were attributed to continuous, intense precipitation due to tropical depressions occurring on the upper Chao Phraya River basin before the rainy season. Thus, unexpected rainfall patterns caused these serious floods. These previous instances indicate that hydrological projections that take into account various precipitation scenarios are important. In addition, since the basin morphology might change owing to flooding, predictions of sediment erosion and transport are necessary.

In the past decade, many studies of the Chao Phraya River basin have been conducted. In 2000, river discharge and water levels in the entire Chao Phraya basin were simulated, including reservoir operation, using a distributed hydrological model (DHM) at a 5-km computing resolution. ${ }^{2)}$ In 2004, 
future hydrological scenarios were forecast by the $\mathrm{SiB} 2$ scheme considering the effects of land use/coverchanges. ${ }^{6}$ )

In this study, we forced the DHM using three general circulation model (GCM) outputs. First, we validated the DHM using the observed rain gauge precipitation. Next, we predicted stream flow scenarios over the next 30 years using the GCM outputs. The qualitative precipitation predictions were modified using the global daily meteorological dataset H08. ${ }^{8)}$

\section{STUDYAREA AND DATA}

\section{(1) STUDY AREA}

The Chao Phraya River originates in the northern high mountains, drains through the central plain, and finally discharges into the Gulf of Thailand. The entire basin covers approximately $160,000 \mathrm{~km}^{2}$, which is one-third of the country. The river basin can be divided geographically into upper, middle, and lower reaches from north to south. Most agricultural land exists in the middle basin (latitude: about $14^{\circ}-17.5^{\circ}$ ). In the upper basin (latitude: $17.5^{\circ}-20^{\circ}$ ), most land is covered by forest or bare soil. The lower basin (latitude: $13.5^{\circ}-14^{\circ}$ ) consists mainly of agricultural and urban areas. The climate is tropical monsoon. The monsoon season runs from May to October, within which about $90 \%$ of the annual rainfall occurs. The annual precipitation is approximately $1500 \mathrm{~mm}$.

The simulated basin set appears inFig.1. It consists of the Ping and Wang river basins (influent rivers of the Chao Phraya River). This area is mountainous, and thus, sudden rainfall is more likely to occur than on the plains. The simulated basin covers an area of $36,285 \mathrm{~km}^{2}$. In the lower basin, the largest dammed reservoir, created by the Bhumipole Dam (drainage area: $26,386 \mathrm{~km}^{2}$, maximum water storage: 13,462 million $\mathrm{m}^{3}$ ) appears. Discharge points are simulated throughout this area. We need to consider the difference between the hydrographs of points in the upper and lower basins of the reservoir. In the basin below the Bhumipole Dam, the hydrograph should be moderate because this large dam correctly reduces flood peaks.

\section{(2) DATA AVAILAVILITY}

The basin topography was simulated by a digital elevation model having a $90-\mathrm{m}$ resolution. The original elevation data were obtained from the Shuttle Radar Topography Mission (URL: http: //www2.jpl.nasa.gov/srtm/dataprod.htm). Land cover information was collected from a 1996 USGS global land use map (Global Land Cover Characteristics Data Base Version 2.0, Simple Biosphere 2 Modelhttp://edc2.usgs.gov/glcc/tabgeo _globe.php.). This map classifies land use into 10 types; the dominant land use types in the study area were broadleaf evergreen trees (40\%), mixed broadleaf and needle leaf trees (23\%), and agricultural land (17\%). Information on the soil water properties was collected from the 2002 global soil type map Digital Soil Map of the World on CD-ROM, based on the Food and Agriculture Organization (FAO)/UNESCO Soil Map of the World. The spatial reference for both land cover and soil types is $1 \mathrm{~km}$. For discharge calibration, observed discharge data from the Thai Royal Irrigation Department were used (Royal Irrigation Department, hydro-1 center in Chainmail, URL: http://www. hydro-1.net/).

Meteorological data were obtained from the Royal Irrigation Department. According to the data quality, the daily rainfall data of four years (2007 to 2010) at 80 gauges were selected for the hydrological simulation. We also used satellite image rainfall data from the Tropical Rainfall Measuring Mission (TRMM; URL: http://www.eorc.jaxa.jp/TRMM/ index_j.htm). TRMM, which was launched by the US National Aeronautics and Space Administration and Japanese Aerospace Exploration Agency in 1997, provides three-hourly rainfall data in tropical areas as a global dataset. The spatial resolution is $0.25^{\circ}$.

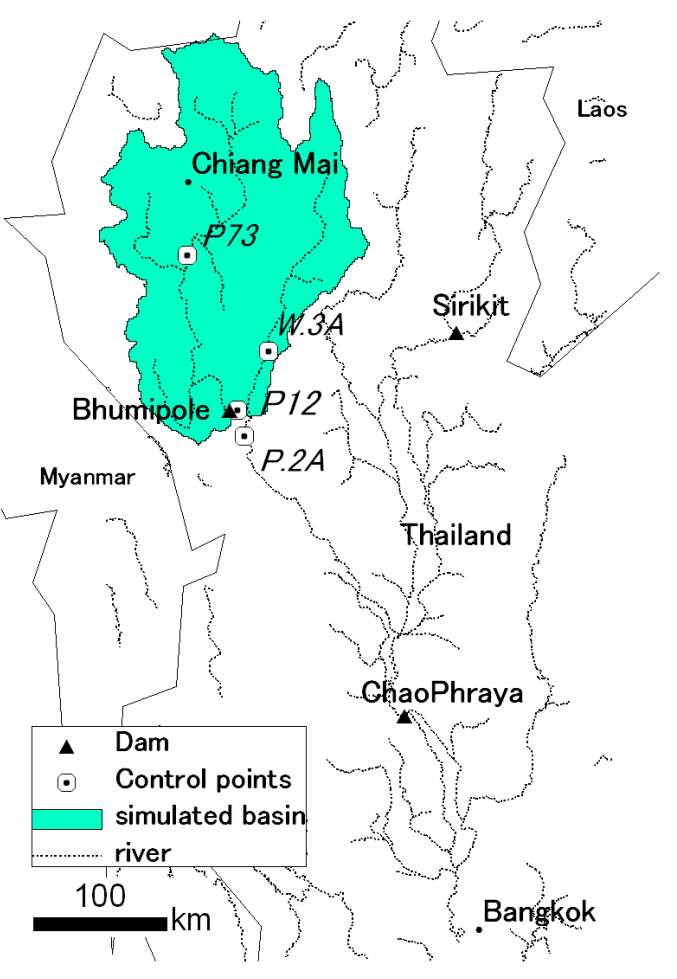

Fig.1 Location of target basin 


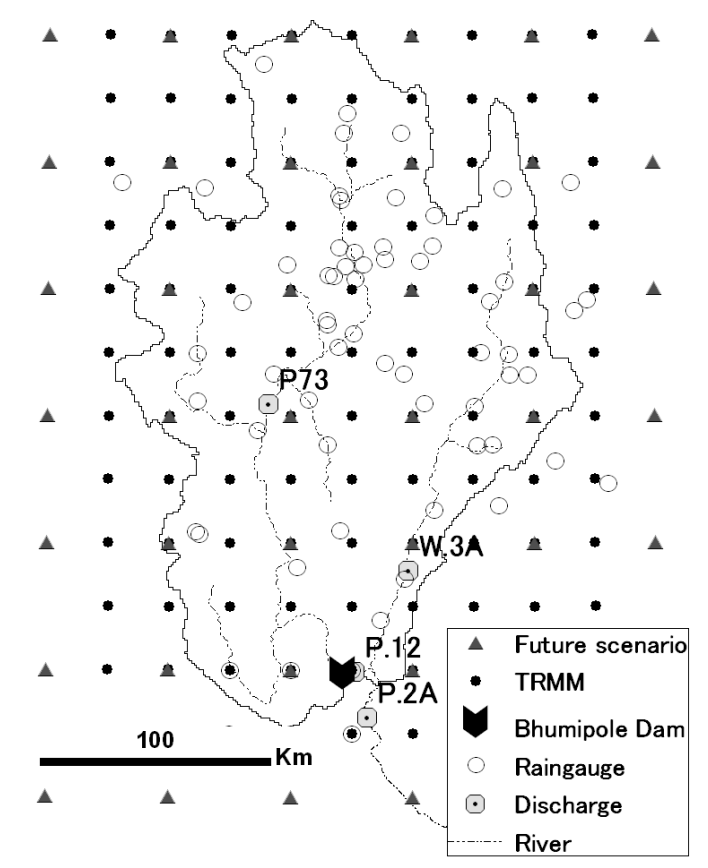

Fig.2 Spatial distribution of rainfall observation points

For future rainfall scenario was taken from future GCM experiments: MIROC $3.2^{9)}$, MPI ECHAM ${ }^{10)}$, CCSM3.0. ${ }^{11)}$ As climate scenario Special Report on Emission Scenarios (SRES) A1B ${ }^{12)}$ indicating in the high economical growth rate was chosen.

The distribution of the available rainfall data is shown in Fig.2. All of the collected meteorological data were adjusted to $1-\mathrm{km}$ resolution for the computation units. To interpolate the rain gauge data in particular, we used the Thiessen polygon method to determine the distance between each pair of rain gauge points.

\section{METHOD}

(a) The hydrological model set-up

To simulate the current and long-term discharge dynamics for the river basin, we used a DHM, the geomorphology-based hydrological model (GBHM). This model's features were physically based on a hydrological model. That is, the water budget at each computational unit was simulated by a hill-slope module, and the lateral inflow was routed downstream by a kinematic wave module. We then obtained the discharge at each gauge point. We chose $1-\mathrm{km}$ grids as computational units. Each computational unit was viewed as a rectangular inclined plane with a defined length and unit width. The inclination angle was given by the surface slope, And the bedrock was assumed to be parallel to the surface. We used the hill-slope element introduced by Yang et $\mathrm{al}^{13)}$.The hill-slope module was applied in computational units having this feature. The module is divided into four parts: storage of precipitation in the soil; precipitation storage in the canopy; water exchange between the saturated layer, unsaturated layer, and the surface; and evapotranspiration from the canopy and the soil. Richard's equation was used to calculate the water exchange between the saturated and unsaturated layers. Darcy's law was used to calculate the water flow in the saturated zone. To simulate transpiration, the Normalized Difference Vegetation Index ${ }^{14)}$ was used to obtain the canopy cover ratio in each computational unit. The landuse type and soil type from the USGS and FAO data determined each parameter of each hill-slope equation, and each parameter was calibrated for each type of soil and land use.

The simulated discharge flowing from each computational unit was accumulated into interval flows, which were identified according to the Pfafstetter Basin Numbering System ${ }^{15)}$.The accumulated discharge was routed from the upper to the lower basin according to the Pfafstetter numbering scheme by using the kinematic wave module. Thus, we obtained the discharge and water levels at each control point.

\section{(b) Model Calibration}

We calibrated the parameters mentioned in the previous section by comparing the discharge simulated using rain gauge data and the observed discharge in 2007. The simulation time step was $1 \mathrm{~h}$. Because only daily precipitation observations were available, they were transformed to hourly data on the basis of the average time distribution in one day. To include the effect of the dam in the simulation, the released flow was assumed to be the same as the observed discharge at P.12 located about $7 \mathrm{~km}$ downstream than the dam (Fig.2).

\section{(c) Improvement of GCM outputs}

Daily future surface temperature and precipitation determined by these introduced GCMs were corrected against the $0.5^{\circ}$ global daily meteorological dataset H08. The daily temperature change was corrected by subtracting the differences between the monthly means for 1961-2000 in the H08 and the GCMs. The daily precipitation was corrected by employing the ratio of the H08 and GCM precipitation intensities in eight different classes (1, $5,10,15,20,25$, and $30 \%$ largest daily intensities and the remaining samples) for 1961-2000. The wet day percentage in each H08 grid for 1961-2000 was scaled by the ratio of the GCMs' wet day percentage for 1961-2000 and five 20-year future periods (2001-2020, 2021-2040, 2041-2060, 2061-2080, and 2081-2100). 
We should be aware that each future climate by GCM simulations does not necessarily show similar characteristics of climate condition of observed climate in short time scale, since scenario simulation by GCMs reflect their own internal climate systems, resulting different time series of SST, monsoon activity and other seasonal to annual climate oscillations.

The daily average precipitation from rain gauge, TRMM and three modified GCM outputs is shown from 2007 to 2009 in Fig.3. It can be seen that rain gauge and TRMM are in close agreement. The three modified model outputs can simulate rainy season properly with some small difference among them.

\section{(d) Scenarios of future river discharge}

We obtained simulated discharge from 2007 to 2040 with modified GCM outputs. Since simulated discharge using modified GCM outputs cannot be forecasted within short training period, our analysis is based on the highest and average peak discharge within three decades.

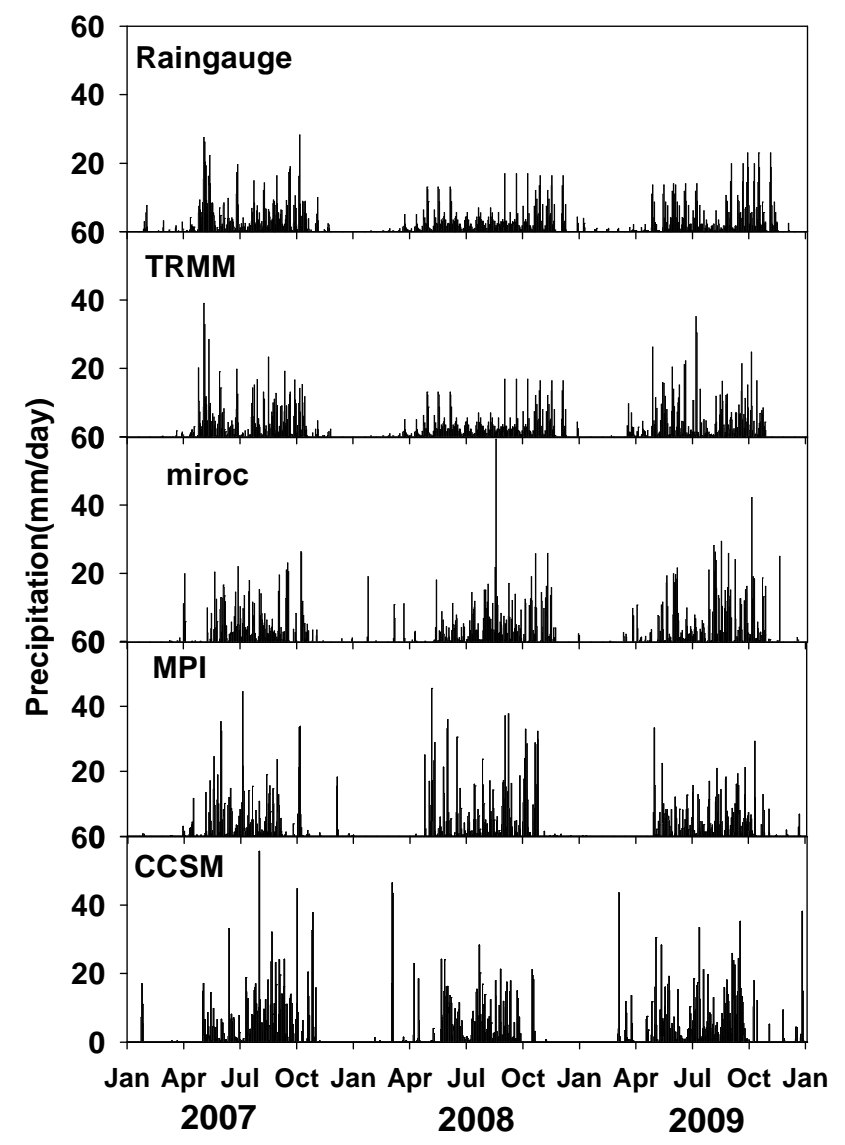

Fig.3 Average precipitation of entire target basin

\section{RESULT AND DISCUSSION}

(a) DHM model set up

The simulated discharge calculated using rain gauge data and TRMM data at P73 and W3A are shown in Fig.4. The discharge at P2A is shown in Fig.5. (Observed discharge data for P2A were not available for 2008.)

The discharge calculated using rain gauge data was close to the observed discharge at P73 and P2A. However, the simulations generally tended to overestimate, especially at W3A. The RMSE of the discharge simulated using rain gauge data versus the observed discharge was equal to $132\left(\mathrm{~m}^{3} / \mathrm{s}\right)$ at $\mathrm{P} 73$, $928\left(\mathrm{~m}^{3} / \mathrm{s}\right)$ at $\mathrm{W} 3 \mathrm{~A}$, and $238\left(\mathrm{~m}^{3} / \mathrm{s}\right)$ at P2A.

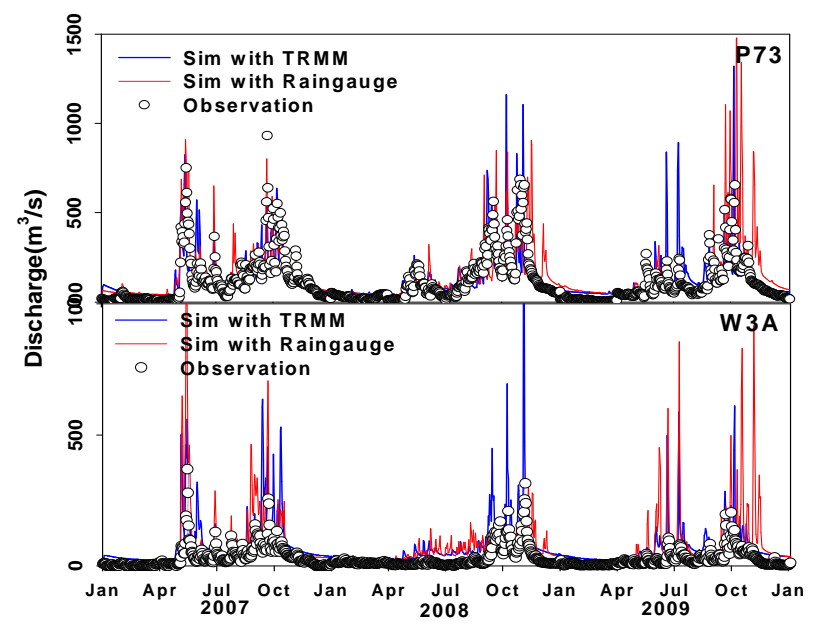

Fig.4 Discharge simulation at P73 andW3A
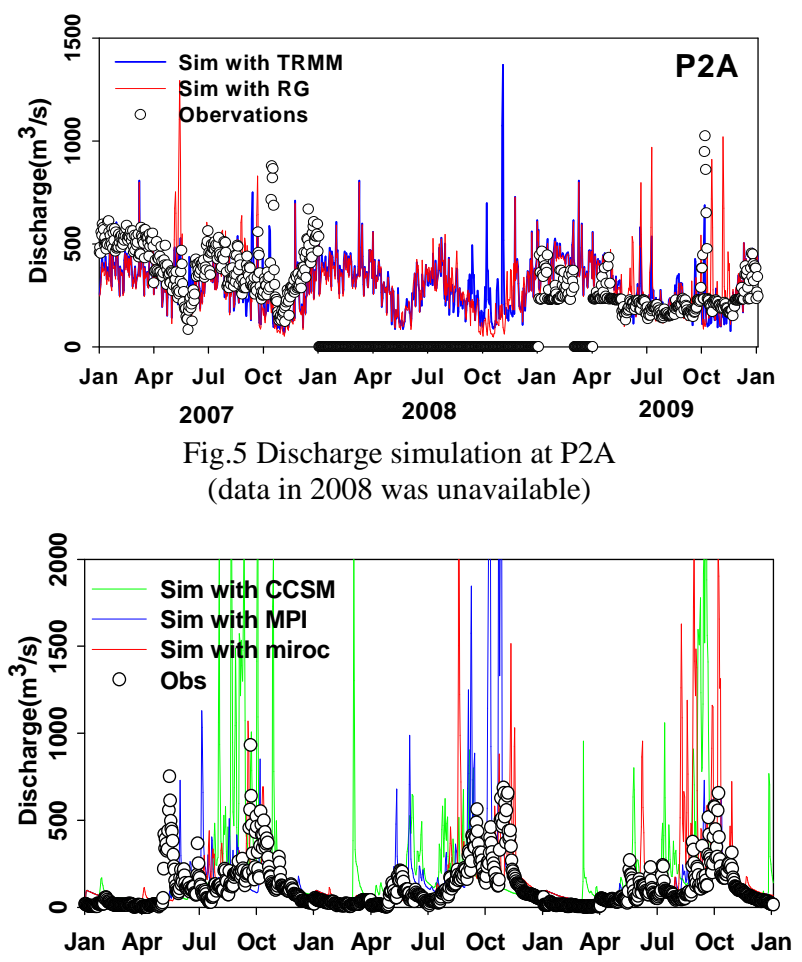

Fig.6 Discharge simulation at P73with GCM outputs 


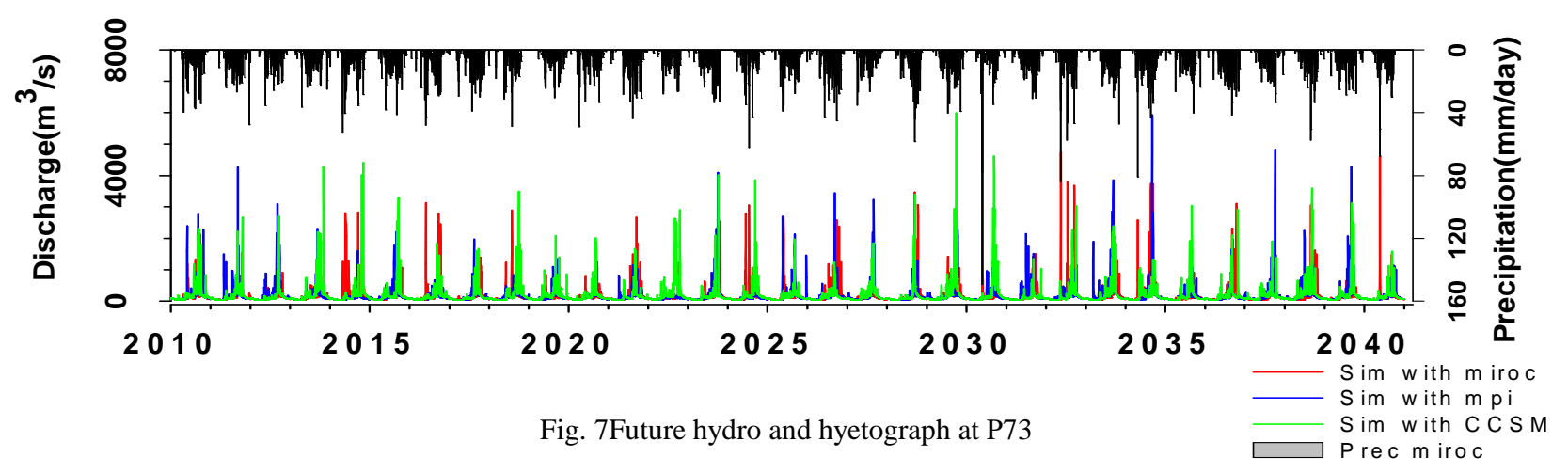

(b) Future hydrological scenarios

Simulated discharge from 2007 to 2009 at P.73 with three precipitation patterns from GCMs are shown in Fig.6. Similar to Fig.3, we show this graph to evaluate the annual seasonality. The simulated discharge was overestimated than observation. Focusing on seasonality, the months with the highest peak discharge simulated are between July and October.

Future hydrographs from 2010 to 2040 were simulated at P73 as shown in Fig.7. In the part of this figure, hyetograph from MIROC output can be seen. A consistent response of the hydrological model (i.e. calculated discharge) in red line using MIROC data can be noticed. Particularly、it is evident for years 2014, 2027 and 2032. Then, we calculated the annual mean and highest discharge in four year groups (2007-2010, 2011-2020, 2021-2030, and 2031-2040) at the stations P73 and W3A, see fig.8 and 9 respectively. From Fig. 8 the mean annual discharge at each decade does not show a high variation. On the other hand, Fig.9 showing the annual highest discharge seems to increase for future decades, especially from 2021 to 2030 . Actually, simulations with MIROC and CCSM output predict higher flood peaks. On the other hand, calculated discharge with MPI does show a clear increment.

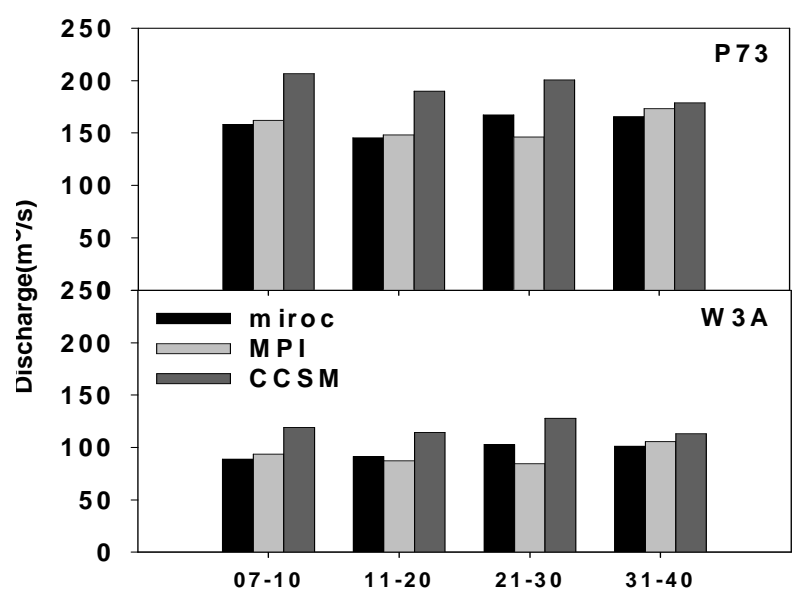

Fig.8 Mean annual discharge at each decade

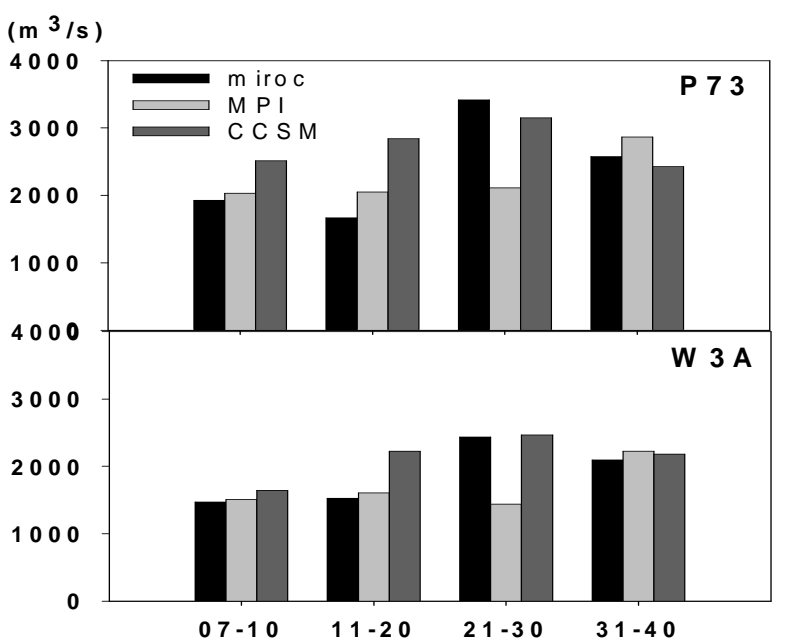

Fig.9 Average of highest discharge at each decade

The frequency of the annual highest discharge at stations P73, W3A was counted as illustrated in Fig.10 and Fig.11. From this figure, the peak timing from MIROC tends to be distributed before the rainy season of each year. On the other hand, the result from CCSM tends to be distributed to after rainy season of each year. Finally, MPI output suggests the flood peak timing will become more concentrated in September.

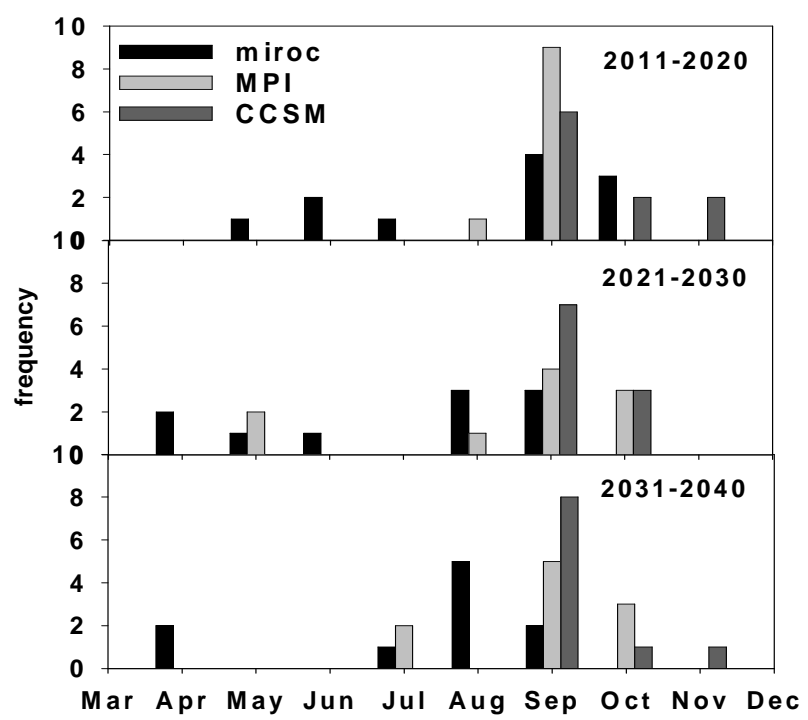

Fig.10 Frequency of the highest discharge at P73 station 


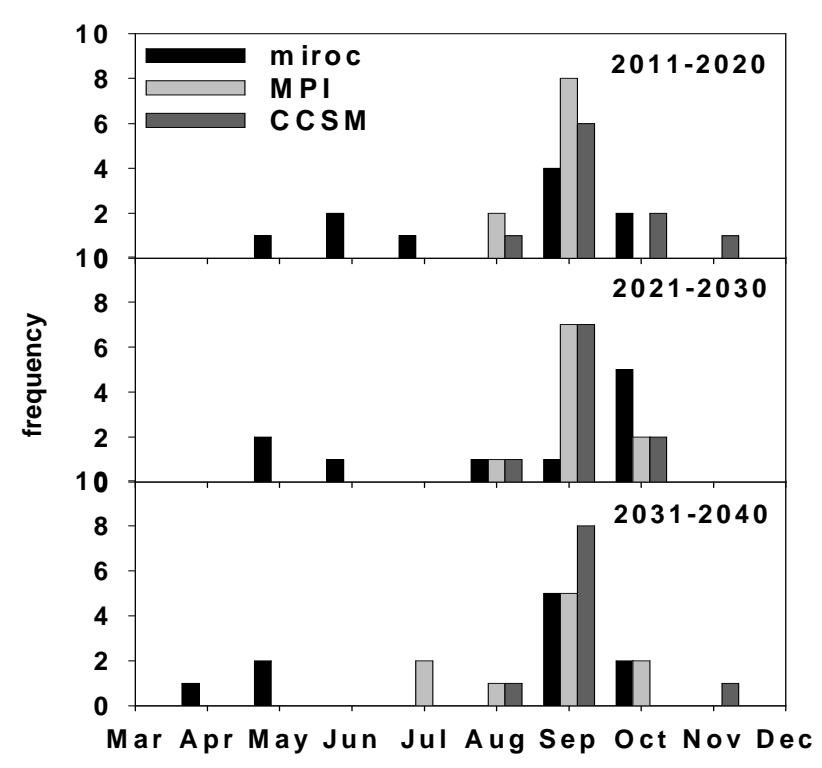

Fig.11Frequency of the annual highest discharge W3A station

\section{CONCLUSION}

In this paper, a distributed hydrological model and the data simulated by modified GCM were applied to Chao Phraya river basin. The overall performance of the DHM model using observed precipitation showed acceptable agreement with observed river discharge. The model overestimated discharge in some areas. Then, future river discharge patterns were predicted forcing the DHM model using three modified GCMs. The results suggest that the mean highest peak discharge might increase within the future three decades. In addition, the higher flood peaks seems to be more concentrated in September in the simulated basin. However, according to MIROC and CCSM will tend to be more spread before and after main rainy season.

In the future, more appropriate bias correction of the GCM output to the river basin is necessary in order to project future hydrology. Hence, long-term comparisons of in situ data and these models' output are essential. Furthermore, to foresee the changes in basin morphology due to future climate scenarios, we will simulate sediment erosion and transportation by adding a sediment transport module to the existing DHM. This information might be helpful for watershed management in the Chao Phraya River basin.

ACKNOWLEDGMENT: This research was supported by JSPS Asian core project. We are grateful for support from members belonging to
Environmental engineering, faculty of engineering, Kasetsart University. Dr. Komoriat University of Tokyo are also thanked for inviting us to IMPACT-T project, additionally we appreciate RID and TMD regional directors met at IMPAC-T project conference for supplying meteorological data .

\section{REFERENCES}

1) USDA. Grain: World Markets and Trade, Foreign Agricultural Service Circular Series, 2007.

2) Yang, D., Herath, S., Oki, T., \& Musiake, K.: Application of Distributed Hydrological Model in the Asian Monsoon Tropic Region with a Perspective of Coupling with Atmospheric Models. Journal of the Meteorological Society of Japan, 79(1B), 373-385,2007

3) Dashmanta, \& Dutta : Analysis of flood disaster trends in Asia (pp. 512-519), Watershed hydrology:proceedings of the International Conference on Water, 2003.

4) IPCC. Climate Change 2007: Working Group I to IV assessment report of the Intergovernmental Panel on Climate Change. IPCC, Geneva, Switzerland 104., 2007

5) Amornthip Paksuchon: Thailand profiles on Disaster Risk Reduction 2011,2011, Asian Disaster Reduction Center, URL:http://www.adrc.asia

6) Phurimon Puneam : Country Profile of Thailand 2010 Asian Disaster Reduction Center URL:http://www.adrc.asia/countryreport/THA/2009/thaila nd2009.pdf

7) Kim, W., Kanae, S., Agata, Y., \& Oki, T.: Simulation of potential impacts of land use/cover changes on surface water fluxes in the Chao Phraya river basin, Thailand. Journal of Geophysical ResearchAtmospheres, 110(D8), 2005

8) Hirabayashi, Y., Kanae, S., Motoya, K., Masuda, K., ouml, \& 11, P. A 59-year (1948-2006) global meteorological forcing data set for land surface models. Part I: Development of daily forcing and assessment of precipitation intencity. Hydrological Research Letters, 2, 36-40, 2008

9) Hasumi,H., \&Emori, S. K-1 Coupled GCM (MIROC) Description, 2004

10) Jungclaus, J. H., Keenlyside, N., Botzet, M., Haak, H., Luo, J. J., Latif, M. Roeckner, E.. Ocean circulation and tropical variability in the coupled model ECHAM5/MPI-OM. Journal of Climate, 19(16), 3952-3972, 2006

11) Collins, W. D., Bitz, C. M., Blackmon, M. L., Bonan, G. B., Bretherton, C. S., Carton, J. A.,Smith, R. D. The Community Climate System Model version 3 (CCSM3). Journal of Climate, 19(11), 2122-2143, 2006

12) Nakicenovic, N., Joseph Alcamo, G. D., Bert de Vries, J. F., \& et.al. (2001). IPCC Special report on Emission scenario.

13) Yang, D., Herath, S., \& Musiake, K.: A hillslope-based hydrological model using catchment area and width functions. Hydrological Sciences Journal-Journal Des Sciences Hydrologiques, 47(1), 49-65, 2002

14) NASA Modis web , URL : http://modis.gsfc.nasa.gov/

15) Verdin, K. L., \&Verdin, J. P.: A topological system for delineation and codification of the Earth's river basins. ,Journal of Hydrology, 218(1-2), 1-12., 1999

(Received September30, 2011) 